7. Reprod. Fertil. (1964) 8, 419-421

BRIEF COMMUNICATION

\title{
INOSITOL CONTENT OF HUMAN SEMEN
}

\author{
D. A. NIXON \\ Physiology Department, St. Mary's Hospital Medical School, London, W.2
}

(Received 21st Fuly 1964)

Mann (1951, 1954) showed that meso-inositol constituted a major component of the seminal vesicle secretion. Hartree (1957) found that in the seminal plasma of man, pig and rabbit inositol existed mainly in the free form, but a substantial percentage of the total inositol was in a combined form in that of cattle, horse and sheep. The function of meso-inositol in the secretions of the male reproductive tract is obscure. In contrast to fructose, it does not appear to influence the motility or respiration of spermatozoa, nor does it influence fructolysis. Mann (1954) has suggested that it may play a part in the maintenance of the osmotic pressure in the seminal vesicle secretion. Hartree (1957) has postulated that it may be an intermediate in the conversion of glucose to fructose; a formation of inositol from glucose has indeed recently been reported in rat seminal vesicle and prostrate slices by Imai (1964).

Through the co-operation of Dr H. A. Davidson it has been possible to examine the meso-inositol concentration in the semen of twenty subjects attending a clinic of the Family Planning Association. The samples were deproteinized with $0.3 \mathrm{~N}-\mathrm{NaOH}$ and $5 \% \mathrm{ZnSO}_{4}$ within $5 \mathrm{hr}$ of ejaculation and estimated for free inositol by the microbiological assay method of Campling \& Nixon (1955). At the same time the fructose concentration was determined by the method of Bacon \& Bell (1948).

The concentrations of inositol and fructose are shown in Table 1, together with data upon which the fertility of the specimen was assessed by Dr Davidson. The range of values obtained for fructose is in agreement with that found by Harvey (1948) and bore no relationship to the inositol concentrations. The sperm count and the overall assessment of the fertility of the specimen were similarly unrelated to the inositol concentration.

The results presented here indicate that the concentration of inositol in human semen is variable and exceeds that normally found in other body fluids (e.g. that in blood by a factor of approximately 100) and does not correlate with the clinical evaluation of the fertility of the specimen. 


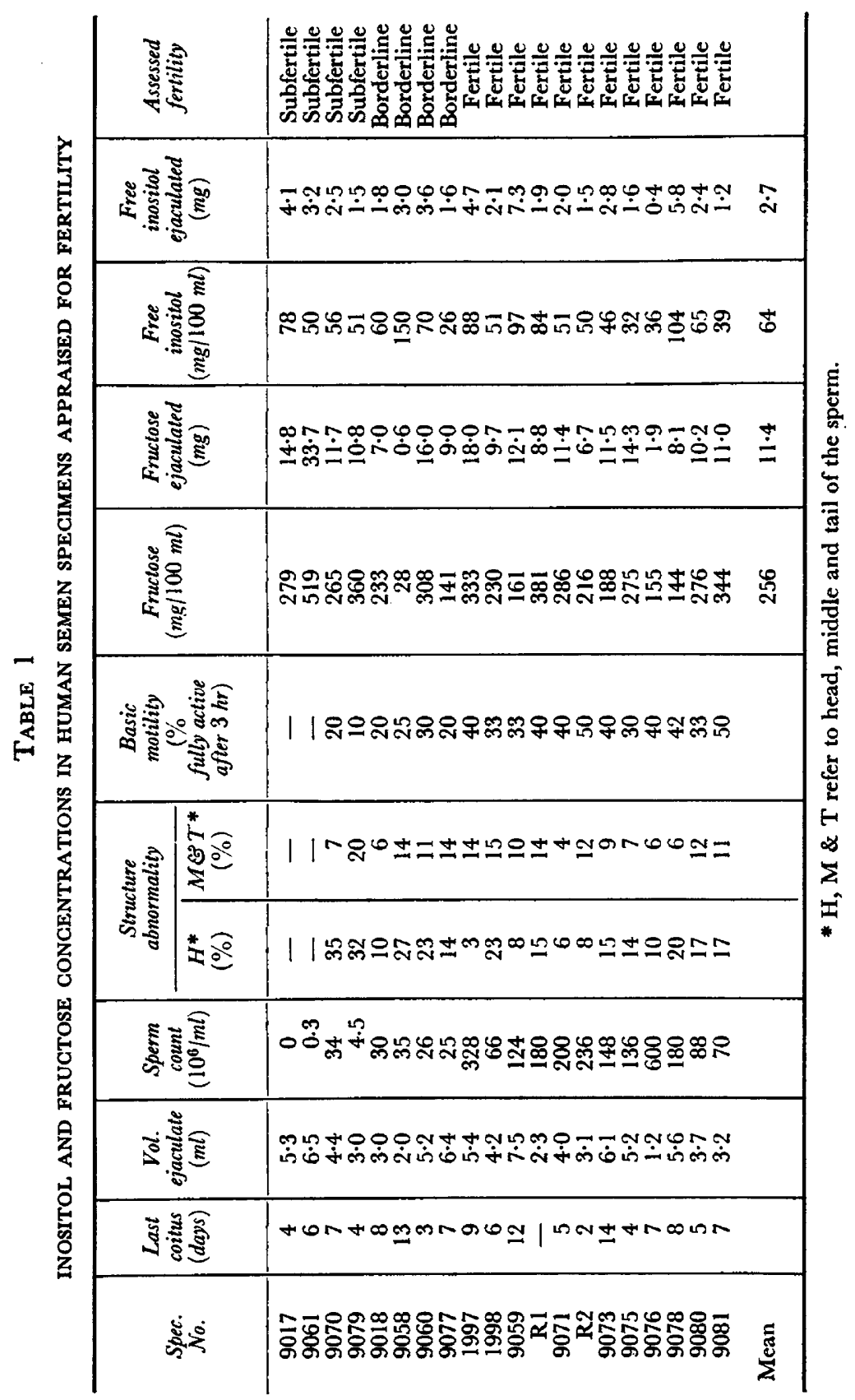




\section{REFERENCES}

Bacon, J. S. D. \& Bell, D. J. (1948) Fructose and glucose in the blood of the foetal sheep. Biochem. F. $42,397$.

Gampling, J. D. \& Nixon, D. A. (1955) The inositol content of foetal blood and foetal fluids. F. Physiol. $129,272$.

HARTREE, E. F. (1957) Inositol in seminal plasma. Biochem. F. 66, 131.

HARVEY, C. (1948) Relation between the volume and fructose content of human semen. Nature, Lond. $162,812$.

ImaI, Yon. (1964) Biosynthesis of mezoinositol in rat seminal vesicles and prostate. F. Biochem. (Tokyo), $55,126$.

MANN, T. (1951) Inositol, a major constituent of the seminal vesicle secretion of the boar. Nature, Lond. 168, 1043 .

ManN, T. (1954) On the presence and role of inositol and certain other substances in the seminal vesicle secretion of the boar. Proc. roy. Soc. B, 142, 21. 